\title{
Substituent Effects on the Binding of Halides by Neutral and Dicationic Bis-Triazolium Receptors
}

\author{
Binod Nepal and Steve Scheiner* \\ Department of Chemistry and Biochemistry \\ Utah State University \\ Logan, UT 84322-0300
}

\begin{abstract}
The effects of substituent and overall charge upon the binding of a halide anion by a bis-triazolium receptor are studied by M06-2X DFT calculations, with the aug-cc-pVDZ basis set. Comparison is also made between a receptor that engages in $\mathrm{H}$-bonds, with a halogen-bonding species. Fluoride is clearly most strongly bound, followed by $\mathrm{Cl}^{-}, \mathrm{Br}^{-}$, and $\mathrm{I}^{-}$in that order. The dicationic receptor engages in stronger complexes, but not by a very wide margin compared to its neutral counterpart. The binding is enhanced as the substituent on the two triazolium rings becomes progressively more electronwithdrawing. Halogen-substituted receptors, whether neutral or cationic, display a greater sensitivity to substituent than do their H-bonding counterparts. Both Coulombic and charge transfer factors obey the latter trends but do not correctly reproduce the stronger halogen vs hydrogen bonding. Both H-bonds and halogen bonds are nearly linear within the complexes, due in part to bond rotations within the receptor that bring the two triazole rings closer to coplanarity with the central benzene ring.
\end{abstract}

*steve.scheiner@usu.edu

Keywords: H-bonds; halogen bonds; molecular electrostatic potential; NBO 


\section{INTRODUCTION}

The selective and efficient binding of anions is an important component in a number of chemical, biological, and environmental processes. There has consequently been a progression of works that are aimed at understanding the fundamentals of this process, and thereby improving it, which would have a number of applications in analytical chemistry, catalysis, and so forth. The majority of anion receptor systems make use of noncovalent interactions between the receptor and the anion. Hydrogen bonds (HBs) are the most common ${ }^{1-4}$ of these binding forces, which are typically strengthened relative to most other HBs by the presence ${ }^{5-7}$ of a full charge on the anion.

However, work in recent years has shown a number of other noncovalent interactions that can be competitive with HBs. For example, highly asymmetric distribution of electron density around electronegative atoms of the chalcogen and pnicogen families allows a means for them to interact attractively with the negatively charged region of a partner ${ }^{8-23}$. The halogen atoms are no exception to this behavior and the rapidly developing exploration ${ }^{19,24-30}$ of the eponymous halogen bonds (XBs) has found application in numerous areas of chemistry, such as molecular recognition ${ }^{31-33}$, organocatalysis ${ }^{34-}$ ${ }^{37}$, and crystal engineering ${ }^{37-43}$.

It is no surprise, then, that $\mathrm{XBs}$ have found recent application to the field of selective anion binding 43-49. Many of the binding agents have been bipodal in nature, with two different halogen atoms connecting to the anion via XBs. These interactions have typically been further strengthened by the presence of positive charge on the receptor. The most common groups binding the anions to date have been derivatives of pyridine ${ }^{48,50-52}$, imidazole ${ }^{53-56}$, and 1,2,3 triazole ${ }^{44,51,57-61}$. These binding groups are typically connected to one another with a spacer group, such as a benzene or pyridine ring.

Recent work from this laboratory ${ }^{62}$ studied the binding of halides to a receptor composed of a pair of 1,2,3-triazole species placed on either side of a separating pyridine ring. The replacement of the $\mathrm{H}$ atoms of the two triazoles by halogen atoms altered the binding, and in particular I-substitution yielded a strong enhancement of the binding of various halides by changing HBs to XBs. Adding positive charge to the receptor furnished another increment to the binding, such that the equilibrium constant could be increased by as much as several orders of magnitude.

However, what this study did not consider at all was how the binding of halides might be affected by the presence of substituents on the receptor. And indeed, this issue of substituent effects represents a gaping hole in our present understanding of differential halide binding, as it has not been examined to date in any systematic manner by either theory or experiment. Based on the major effects that substituents afford to a wide range of chemical properties, e.g. $\mathrm{pK}_{\mathrm{a}}$ and reaction rates to name just two, it 
is easy to imagine a scenario where the judicious choice of a proper substituent could make the difference between an effective and ineffective receptor. In fact, a detailed understanding of substituent effects and their origins might enable the design of a new receptor that has been carefully tuned for optimal desired performance.

The present work addresses this issue in a systematic manner. How strong might these substituent effects be - are they comparable to the rise in binding energy that results from positive charge on the receptor? Do the substituents affect the halogen bonds to the same degree that they alter the H-bonds? Can this effect be evaluated purely on the basis of the electron-withdrawing or donating capacity of the substituent or are there other phenomena that must be considered? What are the principal contributing factors to the binding, and can they be related simply to Coulombic and/or charge transfer? How might the substituents alter the geometries of both the receptors themselves, and the receptor-halide complex? Does the total charge on the receptor carry the same impact on the binding when there are substituents present? Does the strong preference of the receptor for $\mathrm{F}^{-}$over other halides that was found earlier carry over when substituents are present?

In order to answer these questions, the bis-triazole receptor (BTB) shown in Scheme 1 was taken as the starting point. As in many of the systems considered experimentally, I contains a pair of 1,2,3triazole rings, connected to a central benzene unit. The two $\mathrm{H}$ atoms in the $\mathrm{Z}$ position of each triazole are replaced by each of 10 different substituents, chosen to span a wide range of electron-withdrawal or release. The dicationic analogues II were constructed by adding a methyl group on each triazole, as illustrated in the bottom of Scheme I. The binding of each of these receptors to $\mathrm{F}^{-}, \mathrm{Cl}^{-}, \mathrm{Br}^{-}$, and $\mathrm{I}^{-}$was considered so as to span a wide range of different halides.

\section{COMPUTATIONAL METHODS}

Computations were carried out with Gaussian 09, Revision D.01 software ${ }^{63}$. Geometry optimizations along with frequency calculations were performed using the DFT M06-2X density functional ${ }^{64}$ in conjunction with the aug-cc-pVDZ basis set. With heavier elements Br and I, aug-cc-

pVDZ-PP pseudopotentials from the EMSL basis sets library ${ }^{65-66}$ were used. Only geometries with all positive vibrational frequencies were taken into consideration to ensure the obtained structures are in fact true minima. To account for solvent effects, the polarizable conductor calculation model (CPCM) was applied ${ }^{67}$, with water as the solvent. The binding energy of each optimized complex was computed as the difference in energy between the optimized complex and the sum of the energies of separately optimized monomers. The binding energies were corrected for basis sets superposition error (BSSE) 
using the counterpoise procedure ${ }^{68}$. Charge transfer was assessed using the NBO 6.0 program ${ }^{69}$. Molecular electrostatic potentials were calculated via the WFA- SAS program ${ }^{70}$.

\section{RESULTS}

The geometries of a sample subset of complexes are displayed in Fig 1, which illustrate the binding of the $\mathrm{F}^{-}$anion to both neutral and dicationic receptors, with substituent $\mathrm{Z}=\mathrm{NO}_{2}$. The $\mathrm{H}$-bonding species $(\mathrm{X}=\mathrm{H})$ are placed on the left and the halogen-bonding receptors $(\mathrm{X}=\mathrm{I})$ on the right. These geometries are representative of the trends observed throughout. Comparison of Fig 1a with 1c illustrates the contraction of the H-bond lengths that occurs when a charge of +2 is placed on the receptor. The distances of $\mathrm{F}^{-}$to the $\mathrm{X}=\mathrm{I}$ atoms on the right side of Fig 1 are longer, chiefly due to the larger radius of I as compared to $\mathrm{H}$. Again, the dication has shorter halogen bonded distances than does the neutral. Note also that the larger size of I vs $\mathrm{H}$ prevents the third $\mathrm{H} \cdot \mathrm{F}^{-} \mathrm{HB}$ that is present in Figs 1a and 1c from occurring in the halogen-bonded species. In fact, this third $\mathrm{HB}$ is only possible for $\mathrm{Y}^{-} \mathrm{F}^{-}$, which is at least partly responsible for the much stronger bonding of $\mathrm{F}^{-}$as compared to the other halides. Fig 2 provides a broader picture of how the geometries are affected by the nature of the halide, as well as the charge state of the receptor and the identity of the binding atom. The substituent chosen for illustration in Fig 2 is $\mathrm{NH}_{2}$, which is on the opposite end of the electron-donation spectrum from $\mathrm{NO}_{2}$ in Fig 1. The fully optimized geometries of all species discussed below are illustrated in the Supplementary Information, and display very similar trends.

The effects of the various substituents on the binding energy are evident in Fig 3 which represents the neutral receptors. (Numerical data are displayed in Table S1.) As one moves from left to right there is a general trend toward larger binding energy. The broken lines refer to the H-bonding molecules, and the halogen bonding species with $\mathrm{X}=\mathrm{I}$ are indicated by the solid lines. The identity of the halide anion is color coded.

There are several overall trends that are apparent in Fig 3. In most cases, the electron-releasing amino group yields the weakest binding and $\mathrm{NO}_{2}$ the strongest. The solid lines lie above their broken counterparts, which represents the stronger halogen vs H-bonding. This preference for I over $\mathrm{H}$ varies from 1.6 to $5.8 \mathrm{kcal} / \mathrm{mol}$, and is generally larger for the more strongly bound species on the right side of Fig 3. Another clear trend is the diminishing binding strength of the halides in the order $\mathrm{F}^{-}>>\mathrm{Cl}^{-}>\mathrm{Br}^{-}$ $>\mathrm{I}^{-}$, whether by a $\mathrm{H}$ or halogen-bonding agent.

Within the overall trends are several other interesting patterns. For example, the data for the $\mathrm{OCH}_{3}$ substituent suggest a real difference between $\mathrm{H}$ and $\mathrm{X}$ bonding. Methoxy seems to provide anomalously strong binding for the broken curves representing H-bonding, in comparison to their halogen-bonding 
counterparts, indicated by the solid curves. This distinction is perhaps most readily apparent in the comparison with the similar $\mathrm{OH}$ substituent to its immediate right in Fig. 3. Examination of the optimized geometries provides a ready explanation for this apparent paradox. When $\mathrm{X}=\mathrm{H}$, the methyl groups are oriented toward that halide, engaging in weak H-bonding with it. These secondary HBs have $\left(\mathrm{H}^{*} \cdot \mathrm{Y}^{-}\right)$lengths on the order of $3.5 \AA$, which are rather long but there are four such bonds in each case, which have a cumulative effect. In addition, there is a $\mathrm{Y} \rightarrow \sigma^{*}(\mathrm{CH})$ charge transfer observed in the NBO analysis which reinforces this stabilizing effect. However, when $\mathrm{X}=\mathrm{H}$ is replaced by the much bulkier I, the methyl group is forced into the opposite orientation, where any such interaction is impossible. So one can perhaps attribute the "bumps" in the H-bonding broken curves of Fig 2 to this supplementary $\mathrm{CH} \cdot \mathrm{Y}^{-} \mathrm{H}$-bonding.

Another substituent which behaves in a perhaps surprising pattern is - $\mathrm{COOH}$. As displayed in Fig $\mathrm{S} 8$, when $\mathrm{X}=\mathrm{H}$, the $\mathrm{COOH}$ group is oriented with its $-\mathrm{OH}$ turned toward the halide, and cis to the carbonyl O. However, when the $\mathrm{H}$ is replaced by $\mathrm{I},-\mathrm{COOH}$ rotates around by $180^{\circ}$ such that it is its $\mathrm{C}=\mathrm{O}$ which is turned toward the binding halide. On the other hand, this reorientation has little effect upon the energetics, since the - $\mathrm{COOH}$ does not engage in any bonding with the halide in either of these two conformations, and there is little energetic difference between these two orientations.

The addition of a double positive charge on the receptor leads to stronger binding with the halides, as one would expect. The degree of strengthening is illustrated by comparison of Fig 4 with Fig 3 . Whereas the neutral binding agents with $\mathrm{X}=\mathrm{H}$ span a range between 3.9 and $16.6 \mathrm{kcal} / \mathrm{mol}$, the minimum and maximum for the dications are 6.9 and $24.0 \mathrm{kcal} / \mathrm{mol}$, respectively. Similarly, for $\mathrm{X}=\mathrm{I}$, the range for the neutrals is $8.5-21.1 \mathrm{kcal} / \mathrm{mol}$, and that of the dications is $12.8-29.6 \mathrm{kcal} / \mathrm{mol}$. It is perhaps interesting that the enlargement of the binding energies induced by a double positive charge is no larger than this.

It is worth noting as well that the patterns for the dications and neutrals are quite similar, with binding energies rising from left to right, as the substituent alters its character from electron-releasing to withdrawing. Also consistent with the neutrals in Fig 3, the interactions with $\mathrm{X}=\mathrm{I}$ are stronger than with $\mathrm{X}=\mathrm{H}$ for the dications as well. The preference for $\mathrm{I}$ over $\mathrm{H}$ is larger for the dications, but only slightly so. For example, the largest $\mathrm{I} / \mathrm{H}$ difference for the neutrals is $8.1 \mathrm{kcal} / \mathrm{mol}$, which occurs for the $\mathrm{COCH}_{3}$ substituent. The same substituent is responsible for a $9.7 \mathrm{kcal} / \mathrm{mol}$ preference of I over $\mathrm{H}$ for the dications.

The gap between the solid and broken curves in Fig 3 is related to the improved ability of the Isubstituted receptor to bind each halide, relative to the unsubstituted species. This gap is largest for $\mathrm{F}^{-}$, 
roughly $7-8 \mathrm{kcal} / \mathrm{mol}$ for the neutral receptors and $8-10 \mathrm{kcal} / \mathrm{mol}$ for the dications. In terms of an equilibrium constant, $7 \mathrm{kcal} / \mathrm{mol}$ would translate at $25^{\circ} \mathrm{C}$ to a $10^{5}$ enhancement of the binding of fluoride by I-substitution, and this quantity would be as large as $10^{7}$ for the dicationic receptor. The interactions of the other halides are also strengthened by the I-substitution, but not by quite as much, more in the range of 3-6 kcal/mol.

The magnitude of substituent effect is another important parameter. Turning first to the neutral $\mathrm{H}$ bonding receptors, the broken curves in Fig 3, the change of substituent from $\mathrm{NH}_{2}$ to $\mathrm{NO}_{2}$, raises the binding energy by $2-5 \mathrm{kcal} / \mathrm{mol}$, largest for $\mathrm{F}^{-}$and smallest for $\mathrm{I}^{-}$. This same increment is larger for the halogen-bonding receptors in Fig 3, in the range between 3 and $7 \mathrm{kcal} / \mathrm{mol}$. Adding double positive charge to the receptor results in a small increase of roughly $0.5 \mathrm{kcal} / \mathrm{mol}$ in the aforementioned $\mathrm{NO}_{2}-$ $\mathrm{NH}_{2}$ difference for the $\mathrm{H}$-bonding receptors, about $0.7 \mathrm{kcal} / \mathrm{mol}$ for the halogen bonding agents. In summary, the I-substituted receptors, whether neutral or cationic, display a greater sensitivity to substituent than do their H-bonding counterparts.

Just as in the case of the neutrals in Fig 3, the dications also present an anomalously large binding energy for the OMe substituents when $X=H$, as indicated by the broken curves in Fig 4. Again, this effect is the result of secondary H-bonding to the methyl groups. A similar inflation appears in Fig 4 for the $\mathrm{COCH}_{3}$ group which has a similar origin: $\mathrm{CH} \cdot \mathrm{Y}^{-} \mathrm{H}$-bonding. This interaction is absent in the neutrals because the $\mathrm{COCH}_{3}$ group adopts the opposite configuration there, with $\mathrm{CH}_{3}$ trans to the $\mathrm{Y}^{-}$ anion. One may note that the binding energies of the $\mathrm{OH}$ substituent in Fig 4 are also somewhat higher than in Fig 3, relative to the other substituents. Again, secondary H-bonding is the culprit, in this case $\mathrm{OH} \cdot \mathrm{Y}^{-}$.

\section{Electrostatics and Charge Transfer}

The interaction of each receptor with a halide will clearly have a strong electrostatic component. The anion will be attracted toward the positive region of the pertinent atom, whether $\mathrm{H}$ or I. The molecular electrostatic potential (MEP) surrounding each receptor was evaluated on a surface corresponding to an isodensity contour of $0.001 \mathrm{au}$. The maximum value of this potential on the binding atom, either $\mathrm{H}$ or I, and pointing directly toward the incoming halide, is illustrated in Fig 5 for all binding agents, with numerical values displayed in Table S2. The potential is clearly most positive for the dications, shown in red, compared to the neutrals in green. Secondly, the potentials are uniformly higher for $\mathrm{X}=\mathrm{H}$ (broken curves) than for $\mathrm{X}=\mathrm{I}$ (solid). This trend is opposite to the binding energies in Figs 3 and 4 where $\mathrm{X}=\mathrm{I}$ engages in stronger binding with the halides. Another point of difference is related to the magnitudes. As indicated above, the dications bind more strongly to the halides than do 
the neutrals, but not by a wide margin. The dication/neutral ratio of binding energies is between 1.2 and 2.0. In contrast, however, there is a much larger ratio of electrostatic potentials between the charged and neutral species in Fig 5, some three to fourfold. Also, the curves in Fig 5 flatten out toward their right extrema, while the binding energies rise up more quickly, suggesting that the MEP does not adequately represent the effects of the strongly electron-withdrawing substituents. Clearly, then, Coulombic forces cannot be considered the only factor, or perhaps even the dominant one, in the binding of halides.

On the positive side, the rise in the potentials from left to right in Fig 5 does conform at least in a general sense to the trends in the binding energies in Figs 3 and 4. It is interesting to note that the broken green curve in Fig 5, corresponding to the neutral agents with $\mathrm{X}=\mathrm{H}$, shows the same bump at OMe as appears in the four broken curves of Fig 3. This similarity, absent in the solid curves of both figures, indicates that the position of the methyl group has an influence on the MEP commensurate with its effect on the binding energy.

The interaction between an anion and receptor can be expected to lead to a substantial polarization component. That is, the presence of the halide ought to induce a shift in electron density within the binding agent, as well as the obvious transfer of density from halide to receptor. The energetic consequence of such charge shifts can be assessed via the NBO procedure. In the case of a $\mathrm{CH}^{*} \mathrm{Y}^{-} \mathrm{HB}$ for example, the shift of charge from the lone pairs of the halide into the $\sigma^{*}(\mathrm{CH})$ antibonding orbital accounts for a second order perturbation energy $\mathrm{E}(2)$; a similar quantity is calculated for a halogen bond where the charge is transferred into the $\sigma^{*}(\mathrm{IC})$ antibonding orbital. (It should be noted that in a few cases, there is a secondary $\mathrm{HB}$, as for example the $-\mathrm{OCH}_{3}$ substituents mentioned above. In these cases, the $\mathrm{E}(2)$ of these secondary interactions with the halide are included in the data below so as to furnish a more complete treatment of charge transfer.)

These values of E(2) are displayed in Figs 6 and 7 for the neutral and dicationic complexes, respectively, where several familiar trends are again present. (All numerical values are reported in Table S3.) These quantities are larger for the dications than for the neutrals, and become larger from left to right in the figures. They are more reflective of the binding energies than are the MEP maxima in Fig 5 in that the difference between dication and neutral is not overly dramatic. Also, their shapes are rather similar. They both rise at a good clip, even at the right extrema. Both sorts of curves contain the bump at the OMe substituent for the neutrals, for $\mathrm{X}=\mathrm{H}$, but not for $\mathrm{X}=\mathrm{I}$. Regarding the dications, both Figs 4 and 5 contain what appears to be a dip for $\mathrm{X}=\mathrm{H}$ (which is in reality a supplement to the surrounding substituents from secondary interactions). On the other hand, the NBO values are like MEP quantities in that they are both larger for $\mathrm{X}=\mathrm{H}$ than for $\mathrm{X}=\mathrm{I}$, in contrast to the binding energies. However, the larger 
values of $\mathrm{E}(2)$ for $\mathrm{HBs}$ as compared to XBs is not surprising as it is a general feature of $\mathrm{NBO} \mathrm{E}(2)$, in a wide range of different systems ${ }^{71-73}$.

One may ask whether MEP maxima or NBO quantities represent a better means of predicting or measuring binding strength. Figs 8 and 9 display the correlation coefficients in a linear fit of $\mathrm{E}_{\mathrm{b}}$ to each quantity, respectively. The fits are clearly superior for E(2) in Fig 9. For example, the correlation coefficients are especially good for the halogenated binding agents, whether neutral or dicationic, with $\mathrm{R}^{2} \geq 0.97$. One might conclude that the energetic representation of interorbital charge transfer, as encapsulated by $\mathrm{NBO}$, provides a more rigorous reproduction of the full binding energy than does the electrostatic approximation, although neither can be said to be perfect.

\section{$\underline{\text { Geometries }}$}

The charge transferred into the $\sigma^{*}(\mathrm{CH}) /(\mathrm{CI})$ antibonding orbitals is well known to lengthen these covalent bonds upon formation of the relevant complexes ${ }^{74-78}$. The elongation that occurs in these bonds is reported in Table S4 for the various complexes. In summary, the stretches obey many of the same patterns as do the binding energies. They are uniformly larger for the halogen than for the $\mathrm{H}-$ bonded complexes, and the dicationic systems manifest longer elongations than do the neutrals. Also in parallel with the binding energies, the stretches follow the rule $\mathrm{F}^{-}>>\mathrm{Cl}^{-}>\mathrm{Br}^{-}>\mathrm{I}^{-}$. In moving from left to right, i.e. from electron-releasing to electron-withdrawing substituents, there is a clear pattern of increase in the elongation. Regarding the range, the smallest stretch amounts to $0.003 \AA$ for the neutral species H-bonded to $\mathrm{I}^{-}$, and the largest elongation of $0.049 \AA$ A occurs for the cationic halogen-bonded receptor interacting with $\mathrm{F}^{-}$.

Both HBs and XBs have a strong preference for linearity. There is some question as to how the internal restraints within the receptors might accommodate this preference, given their nonplanarity, the difference in length between $\mathrm{CH}$ and $\mathrm{CI}$ bonds, as well as the variable size of the four halides. All of the complexes are able to maintain near linearity, with the largest deviation being only $14^{\circ}$. There is little distinction between H-bonding vs halogen-bonding receptors, nor does the presence of charge or the degree of electron-withdrawing character of the substituent have an appreciable effect. In fact, the only substantive trend is that the small size of the fluoride anion leads to about $5^{\circ}$ larger deviations from linearity than do the other halides.

The unbound receptors are not planar species. The two triazole rings are rotated around the $\mathrm{CN}$ bond connecting them to the central benzene by varying amounts. The $\varphi(\mathrm{CNCC})$ dihedral angle (where the latter two $\mathrm{C}$ atoms lie in the phenyl group) is taken as the measure of this nonplanarity. As displayed in Table S5, this nonplanarity lies in the $28-35^{\circ}$ range for the neutral $\mathrm{H}$-bonding receptor, and becomes 
about $8^{\circ}$ larger for the analogous dication. The much larger size of the I atom leads to greater nonplanarity in the halogen-bonding receptors, averaging $61^{\circ}$ and $69^{\circ}$ in the neutral and dications, respectively.

However, the strong HB forces pull the two triazole rings into much closer coplanarity when the anions are bound (Table S6). The two rings are held within $1^{\circ}$ of coplanarity for the $\mathrm{F}^{-}$anion. Although the larger sizes of the other halides prevent attaining this level of planarity, one can still observe a much diminished $\varphi(\mathrm{CNCC})$. The measure of nonplanarity decreases on average by $16^{\circ}$ upon binding of $\mathrm{Cl}^{-}, 8^{\circ}$ for $\mathrm{Br}^{-}$, and $6^{\circ}$ for $\mathrm{I}^{-}$, consonant with the enlarging sizes of these halides. The corresponding reductions for the dicationic $\mathrm{H}$-bonding receptors are 13,12 , and $7^{\circ}$, respectively. The XBs exert a similar pull trying to bring the two triazole rings closer to coplanarity, but the much larger size of the I atoms opposes this trend, keeping $\varphi(\mathrm{CNCC})$ up around 50-60 . The reduction in this angle arising from binding of the anions is thus only $3-6^{\circ}$ for the neutrals and $6-9^{\circ}$ for the dications.

\section{CONCLUSIONS AND DISCUSSION}

The receptors considered here engage in strongly bound complexes with the various halides, in the order $\mathrm{F}^{-}>>\mathrm{Cl}^{-}>\mathrm{Br}^{-}>\mathrm{I}^{-}$. The binding energies vary from 4 to $21 \mathrm{kcal} / \mathrm{mol}$ for the neutral receptors, rising to the $7-30 \mathrm{kcal} / \mathrm{mol}$ range for dications. In all cases, the replacement of the $\mathrm{H}$ atom of the receptor by I strengthens the interaction. This differential amounts to between 3 and $10 \mathrm{kcal} / \mathrm{mol}$, which equals $20-100 \%$ on a percentage basis. The binding grows steadily stronger as the substituent $\mathrm{Z}$ becomes more electron-withdrawing. The largest increment, that between the $\mathrm{NH}_{2}$ and $\mathrm{NO}_{2}$ substituents, amounts to a $30-50 \%$ rise. Sensitivity to substituent is larger for I-substituted receptors than for their H-bonding counterparts, and dicationic receptors of both sorts show a heightened sensitivity. There are minor deviations from the strict ordering of binding energy with electronwithdrawing capacity of the substituent, most of which can be attributed to direct but weak secondary interactions between the halide and the substituent itself.

The total binding energies can be correlated with their chief contributing forces, viz. Coulombic attraction and charge transfer. The former is measured by the magnitude of the MEP on the $\mathrm{X}=\mathrm{H}$ or I atom to which the halide is attached, and charge transfer is assessed via the NBO second-order perturbation energy. Both of these quantities grow along with the electronegativity of the substituent, but also show certain deviations from the binding energy than do their H-bonding counterparts. Most notably, while the halogen bonding agents $(\mathrm{X}=\mathrm{I})$ engage in tighter complexes with the halides, both MEP and E(2) would suggest the opposite pattern. Nonetheless the NBO charge transfer correlates better with the binding energy than does the MEP. 
The binding produces certain geometrical changes in the receptors. Chief among these is the elongation of the $\mathrm{CH} / \mathrm{CI}$ covalent bonds. These stretches are larger for the halogen than for the $\mathrm{H}$ bonded species, and obey trends very much akin to those observed for the energetics. The receptors are able to mold their shape so as to engage in nearly linear $\mathrm{HBs} / \mathrm{XBs}$ with the bound halide, even accommodating the very large iodide. This linearity is associated with modification of the internal geometry of the receptor, such that the two triazole rings come closer to coplanarity with the central benzene ring than in their unbound state.

Comparison with earlier work ${ }^{62}$ enables conclusions to be drawn concerning the effect of the central group to which the two triazole rings are bound. The earlier calculations used a pyridine rather than a benzene ring as a connector, and the two triazole rings were bound to this connector by one of their $\mathrm{C}$ atoms, rather than $\mathrm{N}$ as here. These changes produced very little effect upon any of the binding energies, with one exception: the H-bonds to fluoride were weakened by some $20-40 \%$.

As one might anticipate in cases involving charged species, there are locations other than the multidentate $\mathrm{H}$-bonding or halogen-bonding sites of interest here that can attract the halide anion. In most cases, the other local minima were of considerably higher energy and thus largely irrelevant to the arguments presented above. The exceptions involved those substituents like - $\mathrm{COOH}$ that contain a highly acidic proton that can engage in a $\mathrm{OH} \cdot \mathrm{X}^{-} \mathrm{HB}$ with the halide. When $\mathrm{F}^{-}$interacts with the carboxyl-substituted receptors, the formation of such a $-\mathrm{COOH} \cdot \cdot \mathrm{F}^{-} \mathrm{HB}$ is energetically preferred over the usual binding site. The same is true for the $-\mathrm{OH}$ substituents which can again engage in a $\mathrm{OH}^{\circ} \cdot \mathrm{F}^{-} \mathrm{HB}$. The ability of such strong proton donors as substituents must therefore be a consideration in the design of halide receptors.

There are other more minor perturbations from the global minimum that occur as secondary minima in a few cases. These other structures involved a rotation of the substituent. Taking $\mathrm{OH}$ as an example, the $\mathrm{H}$ atom could be oriented toward or away from the incoming halide. In the case of the neutral receptors, the $\mathrm{OH}$ favored rotation away from the halide, as depicted in Fig S4. The other conformation was higher in energy by roughly $1 \mathrm{kcal} / \mathrm{mol}$. The dicationic receptors favored the $\mathrm{OH}$ rotated in toward the halide, by something on the order of $5 \mathrm{kcal} / \mathrm{mol}$, also illustrated in Fig S4. Very similar observations apply to several other substituents, specifically $\mathrm{OMe}, \mathrm{COMe}, \mathrm{CHO}$, and $\mathrm{COOH}$. In any case, it is the global minima that are reported and analyzed here.

Although only recently engendering detailed study, the use of halogen bonding receptors to complex with anions has yielded some related principles. While limited to simpler monodentate receptors and not considering halides directly, Sarwar et al ${ }^{79}$ noted a linear free energy relationship between the 
binding constant and substituent constant or calculated MEP of the substituted iodoperfluoroarene $\mathrm{XC}_{6} \mathrm{~F}_{4} \mathrm{I}$ receptors. Like our own findings above these authors noted limitations to a purely electrostatic representation of halogen bonding and differences between halogen bonding and hydrogen bonding. The following year saw the examination of a bipodal halogen-bonding receptor ${ }^{80}$ in concert with halides, but did not explicitly consider substituent effects, also true of slightly later work ${ }^{36}$. A very recent report confirmed our finding that the binding energy increases with diminished size of the halide

${ }^{59}$, as well as the superiority of halogen bonding through I as compared to H-bonding, but again little in the way of substituent effects could be gleaned from this work. The amplification of binding energy resulting from replacement of $\mathrm{H}$ by I had been noted earlier ${ }^{81-83}$, albeit without direct evaluation of substituent effects, and this same effect can be utilized for catalysis ${ }^{51}$. The same principles appear to apply to tripodal receptors ${ }^{56}$ as well.

\section{ACKNOWLEDGMENTS}

Computer, storage and other resources from the Division of Research Computing in the Office of Research and Graduate Studies at Utah State University are gratefully acknowledged.

\section{SUPPORTING INFORMATION}

Numerical values of all binding energies, $\mathrm{V}_{\mathrm{s} . \max }, \mathrm{NBO}$ values of $\mathrm{E}(2)$, geometrical aspects, and diagrams of all optimized geometries. This material is available free of charge via the Internet at http://pubs.acs.org. 


\section{REFERENCES}

1. Hargrove, A. E.; Nieto, S.; Zhang, T.; Sessler, J. L.; Anslyn, E. V. Artificial Receptors for the Recognition of Phosphorylated Molecules. Chem. Rev. 2011, 111, 6603-6782.

2. Malerich, J. P.; Hagihara, K.; Rawal, V. H. Chiral Squaramide Derivatives Are Excellent Hydrogen Bond Donor Catalysts. J. Am. Chem. Soc. 2008, 130, 14416-14417.

3. Doyle, A. G.; Jacobsen, E. N. Small-Molecule H-Bond Donors in Asymmetric Catalysis. Chem. Rev. 2007, 107, 5713-5743.

4. Schreiner, P. R. Metal-Free Organocatalysis through Explicit Hydrogen Bonding Interactions. Chem. Soc. Rev. 2003, 32, 289-296.

5. Nepal, B.; Scheiner, S. Microsolvation of Anions by Molecules Forming $\mathrm{CH} \cdot \mathrm{X}^{-}$Hydrogen Bonds. Chem. Phys. 2015, 463, 137-144.

6. Cybulski, S. M.; Scheiner, S. Hydrogen Bonding and Proton Transfers Involving the Carboxylate Group. J. Am. Chem. Soc. 1989, 111, 23-31.

7. Cybulski, S. M.; Scheiner, S. Comparison of Morokuma and Perturbation Theory Approaches to Decomposition of Interaction Energy. $\left(\mathrm{NH}_{4}\right)^{+} \ldots \mathrm{NH}_{3}$. Chem. Phys. Lett. 1990, 166, 57-64.

8. Desiraju, G. R.; Nalini, V. Database Analysis of Crystal-Structure-Determining Interactions Involving Sulphur: Implications for the Design of Organic Metals. J. Mater. Chem. 1991, 1, 201203.

9. Burling, F. T.; Goldstein, B. M. Computational Studies of Nonbonded Sulfur-Oxygen and Selenium-Oxygen Interactions in the Thiazole and Selenazole Nucleosides. J. Am. Chem. Soc. 1992, 114, 2313-2320.

10. Scheiner, S. On the Properties of X*NN Noncovalent Interactions for First-, Second- and Third-Row X Atoms. J. Chem. Phys. 2011, 134, 164313.

11. Nagao, Y.; Hirata, T.; Goto, S.; Sano, S.; Kakehi, A.; Iizuka, K.; Shiro, M. Intramolecular Nonbonded S... O Interaction Recognized in (Acylimino)Thiadiazoline Derivatives as Angiotensin II Receptor Antagonists and Related Compounds. J. Am. Chem. Soc. 1998, 120, 3104-3110.

12. Iwaoka, M.; Takemoto, S.; Tomoda, S. Statistical and Theoretical Investigations on the Directionality of Nonbonded S...O Interactions. Implications for Molecular Design and Protein Engineering. J. Am. Chem. Soc. 2002, 124, 10613-10620.

13. Nziko, V. d. P. N.; Scheiner, S. Intramolecular S...O Chalcogen Bond as Stabilizing Factor in Geometry of Substituted Phenyl-SF 3 Molecules. J. Org. Chem. 2015, 80, 2356-2363.

14. Nziko, V. d. P. N.; Scheiner, S. Chalcogen Bonding between Tetravalent SF 4 and Amines. J. Phys. Chem. A 2014, 118, 10849-10856.

15. Azofra, L. M.; Scheiner, S. Substituent Effects in the Noncovalent Bonding of $\mathrm{SO}_{2}$ to Molecules Containing a Carbonyl Group. The Dominating Role of the Chalcogen Bond. J. Phys. Chem. A 2014, 118, 3835-3845.

16. Klinkhammer, K. W.; Pyykko, P. Ab Initio Interpretation of the Closed-Shell Intermolecular E*E Attraction in Dipnicogen $\left(\mathrm{H}_{2} \mathrm{E}-\mathrm{EH}_{2}\right)_{2}$ and $(\mathrm{He}-\mathrm{EH})_{2}$ Hydride Model Dimers. Inorg. Chem. 1995, 34, 4134-4138.

17. Scheiner, S. A New Noncovalent Force: Comparison of P...N Interaction with Hydrogen and Halogen Bonds. J. Chem. Phys. 2011, 134, 094315.

18. Bauzá, A.; Mooibroek, T. J.; Frontera, A. The Bright Future of Unconventional $\Sigma / \Pi-H o l e$ Interactions. ChemPhysChem. 2015, 16, 2496-2517.

19. Adhikari, U.; Scheiner, S. Sensitivity of Pnicogen, Chalcogen, Halogen and H-Bonds to Angular Distortions. Chem. Phys. Lett. 2012, 532, 31-35.

20. Bauzá, A.; Quiñonero, D.; Deyà, P. M.; Frontera, A. Pnicogen- $\pi$ Complexes: Theoretical Study and Biological Implications. Phys. Chem. Chem. Phys. 2012, 14, 14061-14066. 
21. Sarkar, S.; Pavan, M. S.; Guru Row, T. N. Experimental Validation of 'Pnicogen Bonding' in Nitrogen by Charge Density Analysis. Phys. Chem. Chem. Phys. 2015, 17, 2330-2334.

22. Del Bene, J. E.; Alkorta, I.; Elguero, J. The Pnicogen Bond in Review: Structures, Energies, Bonding Properties, and Spin-Spin Coupling Constants of Complexes Stabilized by Pnicogen Bonds. In Noncovalent Forces, Scheiner, S., Ed. Springer: Dordrecht, Netherlands, 2015; Vol. 19, pp 191-263.

23. Scheiner, S. The Pnicogen Bond: Its Relation to Hydrogen, Halogen, and Other Noncovalent Bonds. Acc. Chem. Res. 2013, 46, 280-288.

24. Zierkiewicz, W.; Bieńko, D. C.; Michalska, D.; Zeegers-Huyskens, T. Theoretical Investigation of the Halogen Bonded Complexes between Carbonyl Bases and Molecular Chlorine. J. Comput. Chem. 2015, 36, 821-832.

25. Deepa, P.; Pandiyan, B. V.; Kolandaivel, P.; Hobza, P. Halogen Bonds in Crystal Ttf Derivatives: An Ab Initio Quantum Mechanical Study. Phys. Chem. Chem. Phys. 2014, 16, 2038-2047.

26. Adhikari, U.; Scheiner, S. Substituent Effects on Cl $\cdots \mathrm{N}, \mathrm{S} \cdots \mathrm{N}$, and P $\cdots \mathrm{N}$ Noncovalent Bonds. $J$. Phys. Chem. A 2012, 116, 3487-3497.

27. Anable, J. P.; Hird, D. E.; Stephens, S. L.; Zaleski, D. P.; Walker, N. R.; Legon, A. C. Characterisation of the Weak Halogen Bond in $\mathrm{N}_{2} \cdot \cdots \mathrm{ICF}_{3}$ by Pure Rotational Spectroscopy. Chem. Phys. Lett. 2015, 625, 179-185.

28. Politzer, P.; Murray, J. S. A Unified View of Halogen Bonding, Hydrogen Bonding and Other $\sigma$ Hole Interactions. In Noncovalent Forces, Scheiner, S., Ed. Springer: Dordrecht, Netherlands, 2015; Vol. 19, pp 357-389.

29. Scheiner, S. Sensitivity of Noncovalent Bonds to Intermolecular Separation: Hydrogen, Halogen, Chalcogen, and Pnicogen Bonds. CrystEngComm 2013, 15, 3119-3124.

30. Bauzá, A.; Quiñonero, D.; Deyà, P. M.; Frontera, A. Halogen Bonding Versus Chalcogen and Pnicogen Bonding: A Combined Cambridge Structural Database and Theoretical Study. CrystEngComm 2013, 15, 3137-3144.

31. Beyeh, N. K.; Pan, F.; Rissanen, K. A Halogen-Bonded Dimeric Resorcinarene Capsule. Angew. Chem. Int. Ed. 2015, 54, 7303-7307.

32. Jungbauer, S. H.; Bulfield, D.; Kniep, F.; Lehmann, C. W.; Herdtweck, E.; Huber, S. M. Toward Molecular Recognition: Three-Point Halogen Bonding in the Solid State and in Solution. J. Am. Chem. Soc. 2014, 136, 16740-16743.

33. Caronna, T.; Liantonio, R.; Logothetis, T. A.; Metrangolo, P.; Pilati, T.; Resnati, G. Halogen Bonding and $\pi \cdots \pi$ Stacking Control Reactivity in the Solid State. J. Am. Chem. Soc. 2004, 126, 4500-4501.

34. Takeda, Y.; Hisakuni, D.; Lin, C.-H.; Minakata, S. 2-Halogenoimidazolium Salt Catalyzed AzaDiels-Alder Reaction through Halogen-Bond Formation. Org. Lett. 2015, 17, 318-321.

35. Sladojevich, F.; McNeill, E.; Börgel, J.; Zheng, S.-L.; Ritter, T. Condensed-Phase, HalogenBonded $\mathrm{CF}_{3} \mathrm{I}$ and $\mathrm{C}_{2} \mathrm{f}_{5} \mathrm{i}$ Adducts for Perfluoroalkylation Reactions. Angew. Chem. Int. Ed. 2015, $54,3712-3716$.

36. Kniep, F.; Jungbauer, S. H.; Zhang, Q.; Walter, S. M.; Schindler, S.; Schnapperelle, I.; Herdtweck, E.; Huber, S. M. Organocatalysis by Neutral Multidentate Halogen-Bond Donors. Angew. Chem. Int. Ed. 2013, 52, 7028-7032.

37. Walter, S. M.; Kniep, F.; Herdtweck, E.; Huber, S. M. Halogen-Bond-Induced Activation of a Carbon-Heteroatom Bond. Angew. Chem. Int. Ed. 2011, 50, 7187-7191.

38. Mukherjee, A.; Tothadi, S.; Desiraju, G. R. Halogen Bonds in Crystal Engineering: Like Hydrogen Bonds yet Different. Acc. Chem. Res. 2014, 47, 2514-2524. 
39. Cinčić, D.; Friščić, T.; Jones, W. Isostructural Materials Achieved by Using Structurally Equivalent Donors and Acceptors in Halogen-Bonded Cocrystals. Chem. Eur. J. 2008, 14, 747753.

40. Cao, D.; Hong, M.; Blackburn, A. K.; Liu, Z.; Holcroft, J. M.; Stoddart, J. F. Two-Point Halogen Bonding between 3,6-Dihalopyromellitic Diimides. Chem. Sci. 2014, 5, 4242-4248.

41. Bruce, D. W.; Metrangolo, P.; Meyer, F.; Pilati, T.; Präsang, C.; Resnati, G.; Terraneo, G.; Wainwright, S. G.; Whitwood, A. C. Structure-Function Relationships in Liquid-Crystalline Halogen-Bonded Complexes. Chem. Eur. J. 2010, 16, 9511-9524.

42. Turunen, L.; Beyeh, N. K.; Pan, F.; Valkonen, A.; Rissanen, K. Tetraiodoethynyl Resorcinarene Cavitands as Multivalent Halogen Bond Donors. Chem. Commun. 2014, 50, 15920-15923.

43. Troff, R. W.; Mäkelä, T.; Topić, F.; Valkonen, A.; Raatikainen, K.; Rissanen, K. Alternative Motifs for Halogen Bonding. Eur. J. Org. Chem. 2013, 2013, 1617-1637.

44. Schulze, B.; Schubert, U. S. Beyond Click Chemistry - Supramolecular Interactions of 1,2,3Triazoles. Chem. Soc. Rev. 2014, 43, 2522-2571.

45. Ghosh, S.; Mishra, M. K.; Kadambi, S. B.; Ramamurty, U.; Desiraju, G. R. Designing Elastic Organic Crystals: Highly Flexible Polyhalogenated N-Benzylideneanilines. Angew. Chem. Int. Ed. 2015, 54, 2674-2678.

46. Beale, T. M.; Chudzinski, M. G.; Sarwar, M. G.; Taylor, M. S. Halogen Bonding in Solution: Thermodynamics and Applications. Chem. Soc. Rev. 2013, 42, 1667-1680.

47. Metrangolo, P.; Resnati, G. Halogen Versus Hydrogen. Science 2008, 321, 918-919.

48. Langton, M. J.; Robinson, S. W.; Marques, I.; Félix, V.; Beer, P. D. Halogen Bonding in Water Results in Enhanced Anion Recognition in Acyclic and Rotaxane Hosts. Nat Chem 2014, 6, 10391043.

49. Lim, J. Y. C.; Beer, P. D. Superior Perrhenate Anion Recognition in Water by a Halogen Bonding Acyclic Receptor. Chem. Commun. 2015, 51, 3686-3688.

50. Robinson, S. W.; Mustoe, C. L.; White, N. G.; Brown, A.; Thompson, A. L.; Kennepohl, P.; Beer, P. D. Evidence for Halogen Bond Covalency in Acyclic and Interlocked Halogen-Bonding Receptor Anion Recognition. J. Am. Chem. Soc. 2015, 137, 499-507.

51. Jungbauer, S. H.; Huber, S. M. Cationic Multidentate Halogen-Bond Donors in Halide Abstraction Organocatalysis: Catalyst Optimization by Preorganization. J. Am. Chem. Soc. 2015, 137, 1211012120.

52. Kniep, F.; Walter, S. M.; Herdtweck, E.; Huber, S. M. 4,4'-Azobis(Halopyridinium) Derivatives: Strong Multidentate Halogen-Bond Donors with a Redox-Active Core. Chem. Eur. J. 2012, 18, 1306-1310.

53. Zapata, F.; Caballero, A.; White, N. G.; Claridge, T. D. W.; Costa, P. J.; Félix, V.; Beer, P. D. Fluorescent Charge-Assisted Halogen-Bonding Macrocyclic Halo-Imidazolium Receptors for Anion Recognition and Sensing in Aqueous Media. J. Am. Chem. Soc. 2012, 134, 11533-11541.

54. Walter, S. M.; Kniep, F.; Rout, L.; Schmidtchen, F. P.; Herdtweck, E.; Huber, S. M. Isothermal Calorimetric Titrations on Charge-Assisted Halogen Bonds: Role of Entropy, Counterions, Solvent, and Temperature. J. Am. Chem. Soc. 2012, 134, 8507-8512.

55. Caballero, A.; White, N. G.; Beer, P. D. A Bidentate Halogen-Bonding Bromoimidazoliophane Receptor for Bromide Ion Recognition in Aqueous Media. Angew. Chem., Int. Ed. Engl. 2011, 50, 1845-1848.

56. Chakraborty, S.; Dutta, R.; Ghosh, P. Halogen Bonding Assisted Selective Removal of Bromide. Chem. Commun. 2015, 51, 14793-14796.

57. Zapata, F.; Gonzalez, L.; Caballero, A.; Alkorta, I.; Elguero, J.; Molina, P. Dual Role of the 1,2,3Triazolium Ring as a Hydrogen-Bond Donor and Anion- $\Pi$ Receptor in Anion-Recognition Processes. Chem. Eur. J. 2015, 21, 9797-9808. 
58. Kilah, N. L.; Wise, M. D.; Serpell, C. J.; Thompson, A. L.; White, N. G.; Christensen, K. E.; Beer, P. D. Enhancement of Anion Recognition Exhibited by a Halogen-Bonding Rotaxane Host System. J. Am. Chem. Soc. 2010, 132, 11893-11895.

59. Tepper, R.; Schulze, B.; Jäger, M.; Friebe, C.; Scharf, D. H.; Görls, H.; Schubert, U. S. Anion Receptors Based on Halogen Bonding with Halo-1,2,3-Triazoliums. J. Org. Chem. 2015, 80, 31393150.

60. Kniep, F.; Rout, L.; Walter, S. M.; Bensch, H. K. V.; Jungbauer, S. H.; Herdtweck, E.; Huber, S. M. 5-Iodo-1,2,3-Triazolium-Based Multidentate Halogen-Bond Donors as Activating Reagents. Chem. Commun. 2012, 48, 9299-9301.

61. Lim, J. Y. C.; Cunningham, M. J.; Davis, J. J.; Beer, P. D. Halogen Bonding-Enhanced Electrochemical Halide Anion Sensing by Redox-Active Ferrocene Receptors. Chem. Commun. 2015, 51, 14640-14643.

62. Nepal, B.; Scheiner, S. Competitive Halide Binding by Halogen Versus Hydrogen Bonding: BisTriazole Pyridinium. Chem. Eur. J. 2015, 21, 13330-13335.

63. Frisch, M. J.; Trucks, G. W.; Schlegel, H. B.; Scuseria, G. E.; Robb, M. A.; Cheeseman, J. R.; Scalmani, G.; Barone, V.; Mennucci, B.; Petersson, G. A., et al. Gaussian 09, Revision B.01; Wallingford, CT, 2009.

64. Zhao, Y.; Truhlar, D. G. The M06 Suite of Density Functionals for Main Group Thermochemistry, Thermochemical Kinetics, Noncovalent Interactions, Excited States, and Transition Elements: Two New Functionals and Systematic Testing of Four M06-Class Functionals and 12 Other Functionals. Theor. Chem. Acc. 2008, 120, 215-241.

65. Feller, D. The Role of Databases in Support of Computational Chemistry Calculations. J. Comput. Chem. 1996, 17, 1571-1586.

66. Schuchardt, K. L.; Didier, B. T.; Elsethagen, T.; Sun, L.; Gurumoorthi, V.; Chase, J.; Li, J.; Windus, T. L. Basis Set Exchange: A Community Database for Computational Sciences. J. Chem. Infor. Model. 2007, 47, 1045-1052.

67. Barone, V.; Cossi, M. Quantum Calculation of Molecular Energies and Energy Gradients in Solution by a Conductor Solvent Model. J. Phys. Chem. A 1998, 102, 1995-2001.

68. Boys, S. F.; Bernardi, F. The Calculation of Small Molecular Interactions by the Differences of Separate Total Energies. Some Procedures with Reduced Errors. Mol. Phys. 1970, 19, 553-566.

69. Glendening, E. D.; Landis, C. R.; Weinhold, F. NBO 6.0: Natural Bond Orbital Analysis Program. J. Comput. Chem. 2013, 34, 1429-1437.

70. Bulat, F. A.; Toro-Labbé, A.; Brinck, T.; Murray, J. S.; Politzer, P. Quantitative Analysis of Molecular Surfaces: Areas, Volumes, Electrostatic Potentials and Average Local Ionization Energies. J. Mol. Model. 2010, 16, 1679-1691.

71. Scheiner, S. Comparison of $\mathrm{CH} \cdots \mathrm{O}, \mathrm{SH} \cdots \mathrm{O}$, Chalcogen, and Tetrel Bonds Formed by Neutral and Cationic Sulfur-Containing Compounds. J. Phys. Chem. A 2015, 119, 9189-9199.

72. Azofra, L. M.; Scheiner, S. Complexation of $\mathrm{n} \mathrm{SO}_{2}$ Molecules $(\mathrm{n}=1,2,3)$ with Formaldehyde and Thioformaldehyde. J. Chem. Phys. 2014, 140, 034302.

73. Scheiner, S. Detailed Comparison of the Pnicogen Bond with Chalcogen, Halogen and Hydrogen Bonds. Int. J. Quantum Chem. 2013, 113, 1609-1620.

74. Donoso-Tauda, O.; Jaque, P.; Elguero, J.; Alkorta, I. Traditional and Ion-Pair Halogen-Bonded Complexes between Chlorine and Bromine Derivatives and a Nitrogen-Heterocyclic Carbene. $J$. Phys. Chem. A 2014, 118, 9552-9560.

75. Bauzá, A.; Alkorta, I.; Frontera, A.; Elguero, J. On the Reliability of Pure and Hybrid DFT Methods for the Evaluation of Halogen, Chalcogen, and Pnicogen Bonds Involving Anionic and Neutral Electron Donors. J. Chem. Theory Comput. 2013, 9, 5201-5210. 
76. Biswal, H. S. Hydrogen Bonds Involving Sulfur: New Insights from Ab Initio Calculations and Gas Phase Laser Spectroscopy. In Noncovalent Forces, Scheiner, S., Ed. Springer: Dordrecht, Netherlands, 2015; Vol. 19, pp 15-45.

77. Nziko, V. d. P. N.; Scheiner, S. S $\cdots \Pi$ Chalcogen Bonds between $\mathrm{SF}_{2}$ or $\mathrm{SF}_{4}$ and C-C Multiple Bonds. J. Phys. Chem. A 2015, 119, 5889-5897.

78. Nepal, B.; Scheiner, S. Anionic $\mathrm{CH}^{\cdots} \mathrm{X}^{-}$Hydrogen Bonds: Origin of Their Strength, Geometry, and Other Properties. Chem. Eur. J. 2015, 21, 1474-1481.

79. Sarwar, M. G.; Dragisic, B.; Salsberg, L. J.; Gouliaras, C.; Taylor, M. S. Thermodynamics of Halogen Bonding in Solution: Substituent, Structural, and Solvent Effects. J. Am. Chem. Soc. 2010, 132, 1646-1653.

80. Chudzinski, M. G.; McClary, C. A.; Taylor, M. S. Anion Receptors Composed of Hydrogen- and Halogen-Bond Donor Groups: Modulating Selectivity with Combinations of Distinct Noncovalent Interactions. J. Am. Chem. Soc. 2011, 133, 10559-10567.

81. Gilday, L. C.; White, N. G.; Beer, P. D. Halogen- and Hydrogen-Bonding Triazole-Functionalised Porphyrin-Based Receptors for Anion Recognition. Dalton Trans. 2013, 42, 15766-15773.

82. Caballero, A.; Swan, L.; Zapata, F.; Beer, P. D. Iodide-Induced Shuttling of a Halogen- and Hydrogen-Bonding Two-Station Rotaxane. Angew. Chem. Int. Ed. 2014, 53, 11854-11858.

83. Mercurio, J. M.; Knighton, R. C.; Cookson, J.; Beer, P. D. Halotriazolium Axle Functionalised [2]Rotaxanes for Anion Recognition: Investigating the Effects of Halogen-Bond Donor and Preorganisation. Chem. Eur. J. 2014, 20, 11740-11749. 


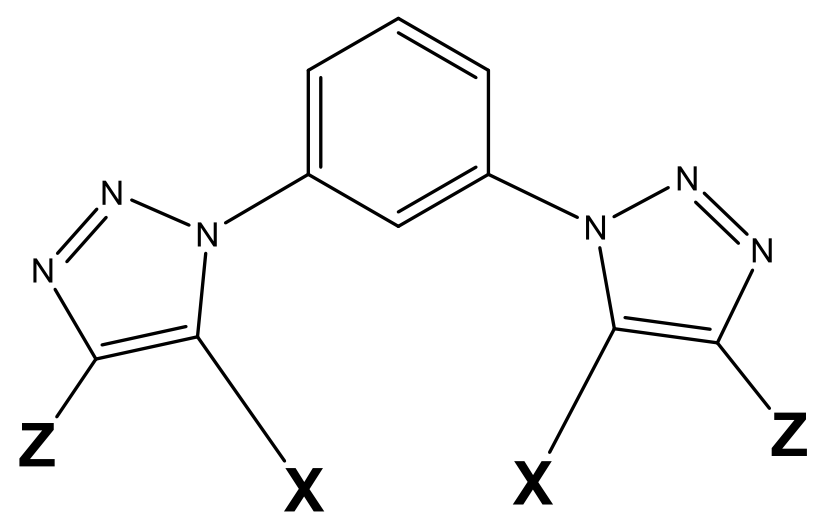

I, neutral

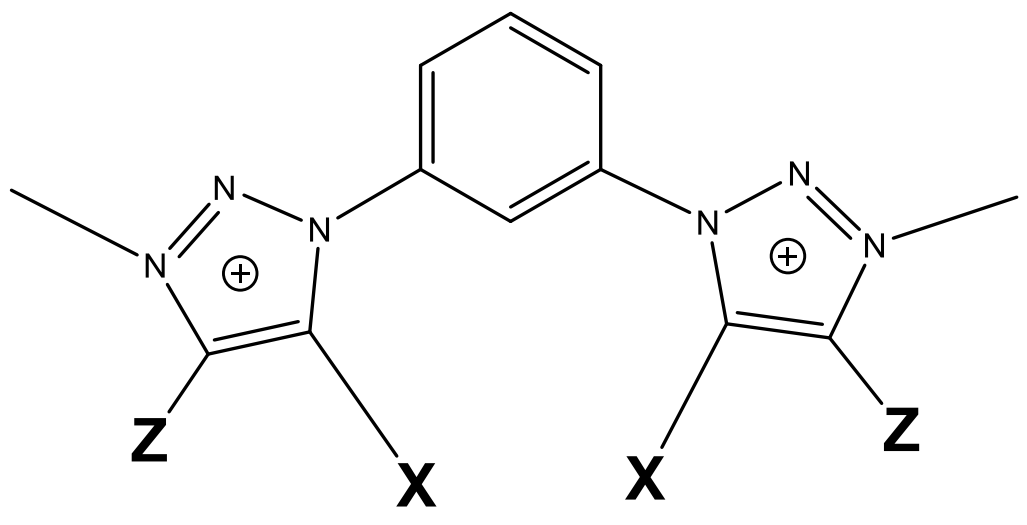

II, dication

$$
\mathbf{X}=\mathbf{H}, \mathbf{I}
$$

\section{$\mathrm{Z}=\mathrm{H}, \mathrm{Me}, \mathrm{OH}, \mathrm{OMe}, \mathrm{NH}_{2}, \mathrm{NO}_{2}, \mathrm{CHO}, \mathrm{COOH}, \mathrm{COMe}, \mathrm{CN}, \mathrm{CF}_{3}$}

Scheme 1. Neutral (I) and dicationic (II) bis-triazole benzene (BTB) receptors. 


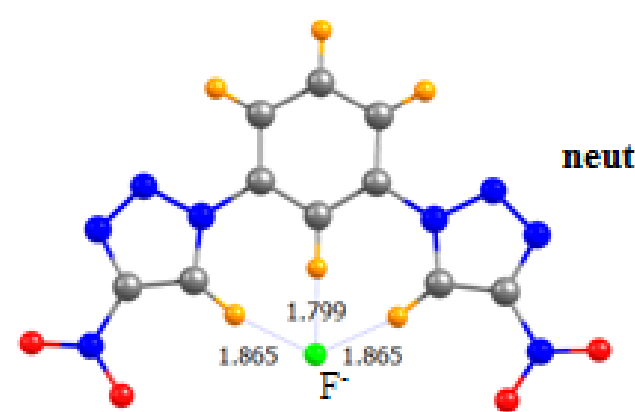

a) $X=H$

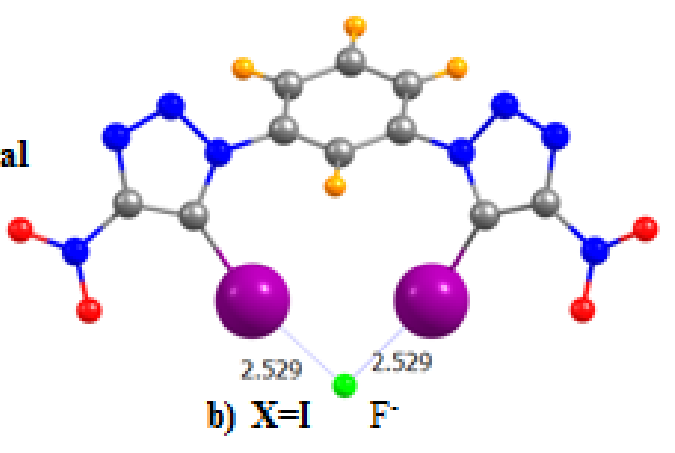

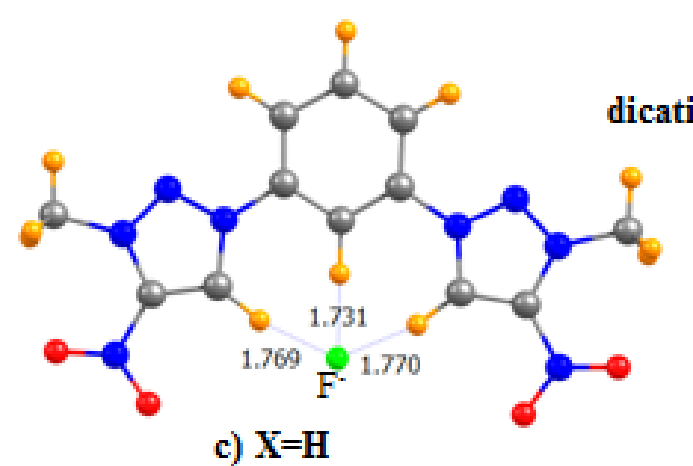

c) $X=H$

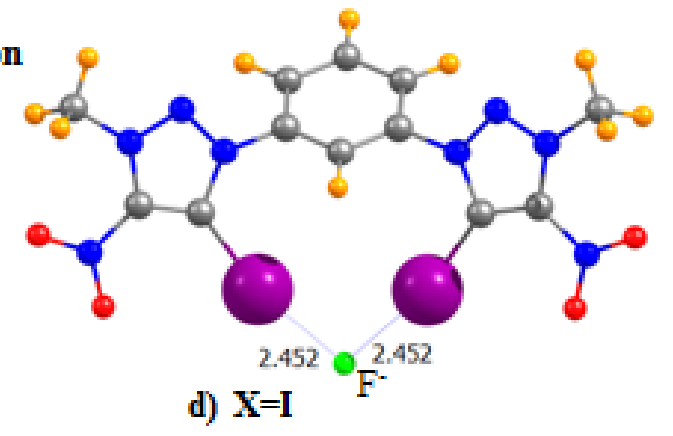

Fig 1. Optimized geometries of complexes of $\mathrm{F}^{-}$with neutral and dicationic BTB receptors with $\mathrm{X}=\mathrm{H}$ (a and c) and $\mathrm{X}=\mathrm{I}$ (b and d). Distances in $\AA$. C, N, I, O, and $\mathrm{H}$ atoms are grey, blue, purple, red, and orange, respectively. 

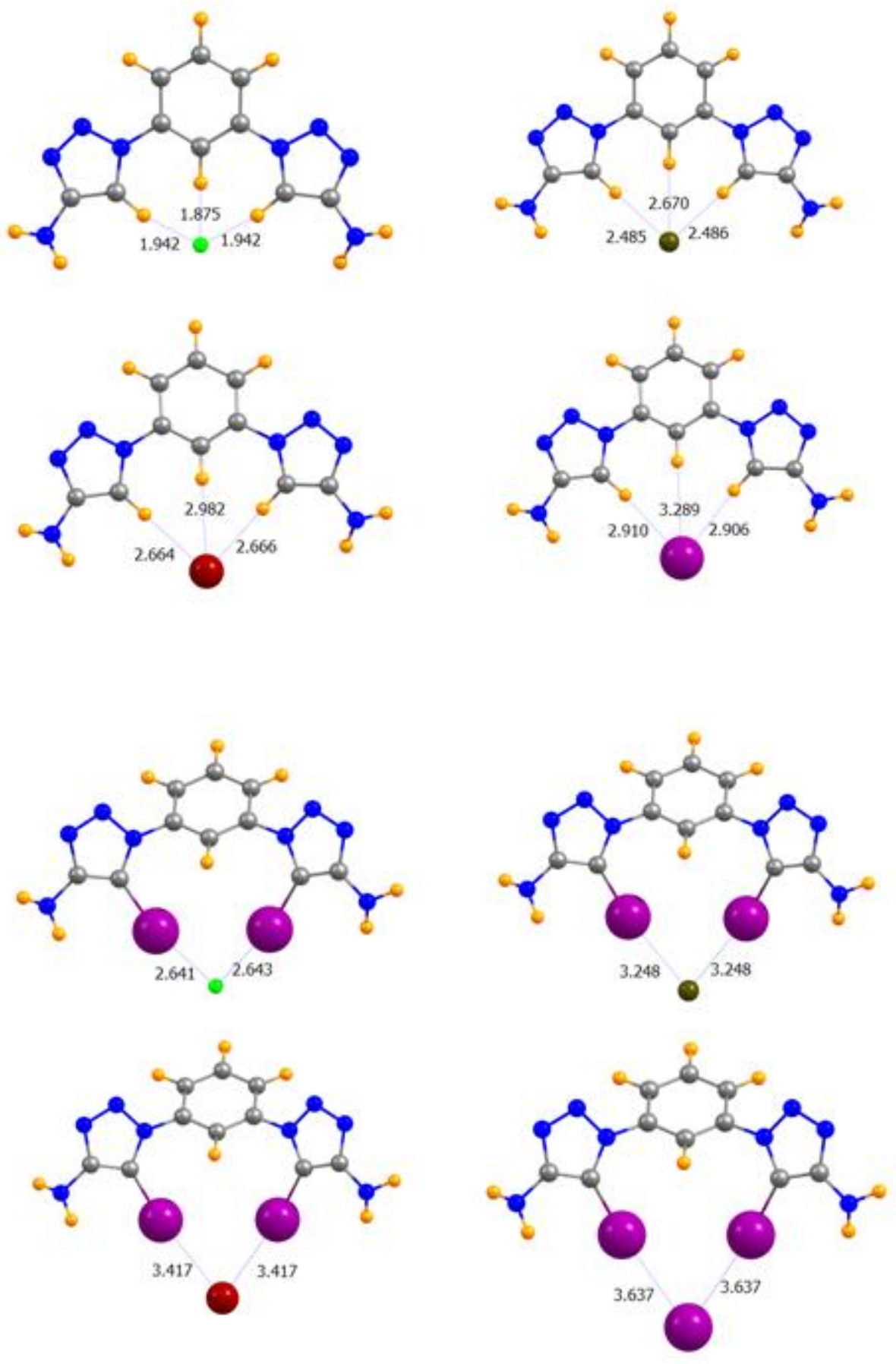

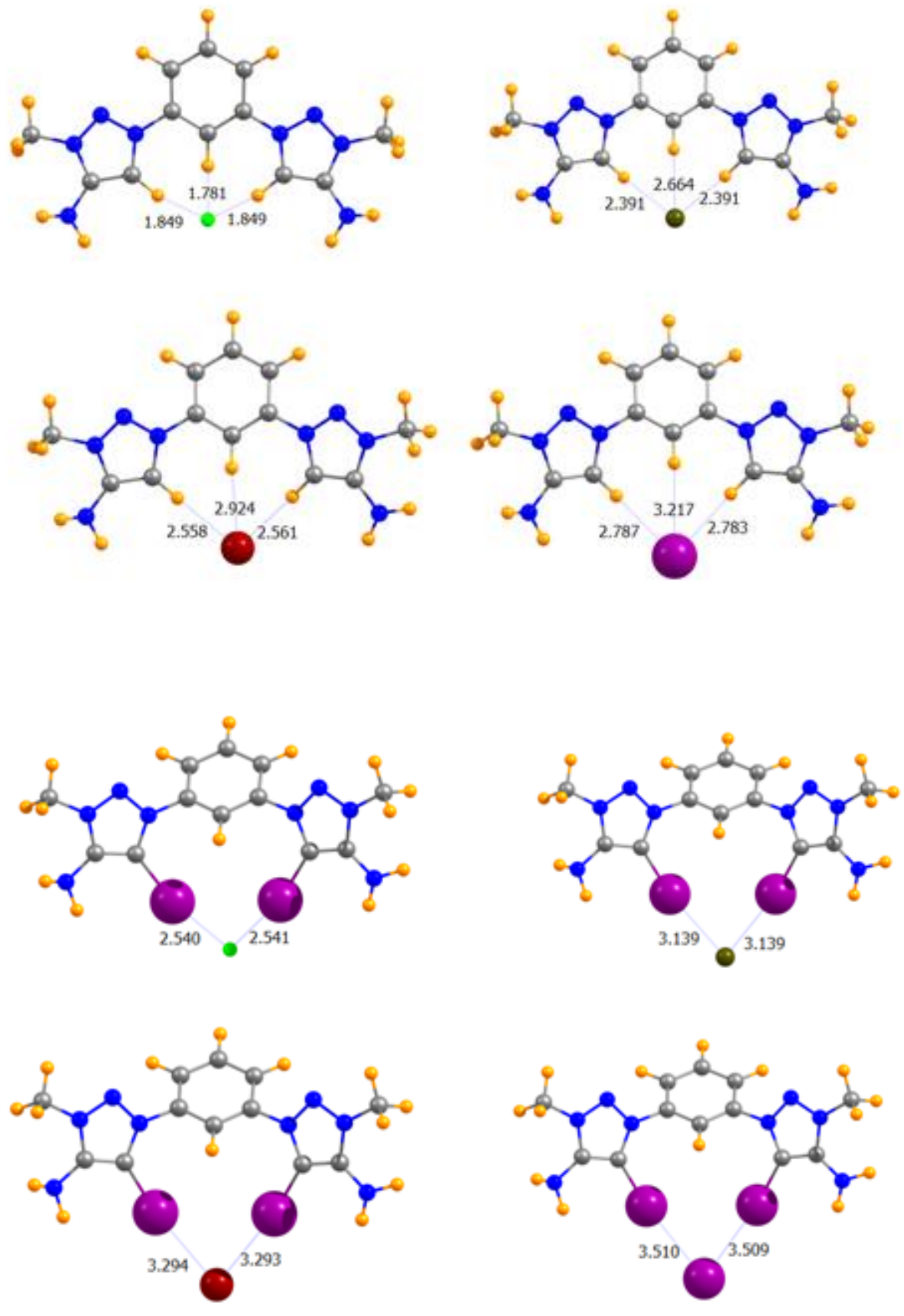

Fig 2. Optimized geometries of complexes of halides with neutral and dicationic BTB receptors with $\mathrm{X}=\mathrm{NH}_{2}$. Distances in $\AA$. C, N, I, and H atoms are grey, blue, purple, and orange, respectively. 


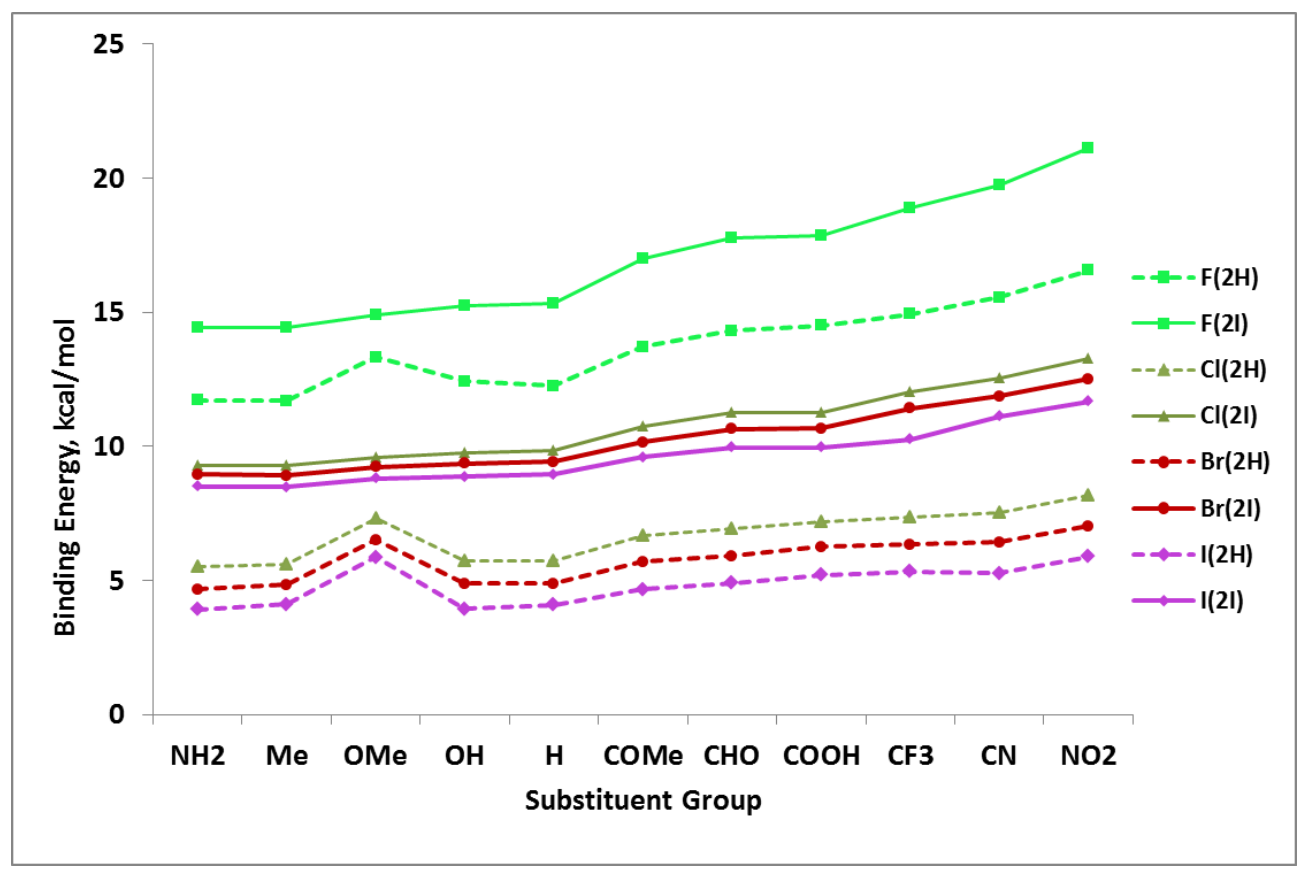

Fig 3. Binding energy of halides $\left(\mathrm{Y}^{-}\right)$to neutral receptors BTB with different substituent groups $\mathrm{Z}$. 2H indicates $\mathrm{H}$-bonding complexes $(\mathrm{X}=\mathrm{H})$ and $2 \mathrm{I}$ refers to halogen-bonding complexes with $\mathrm{X}=\mathrm{I}$.

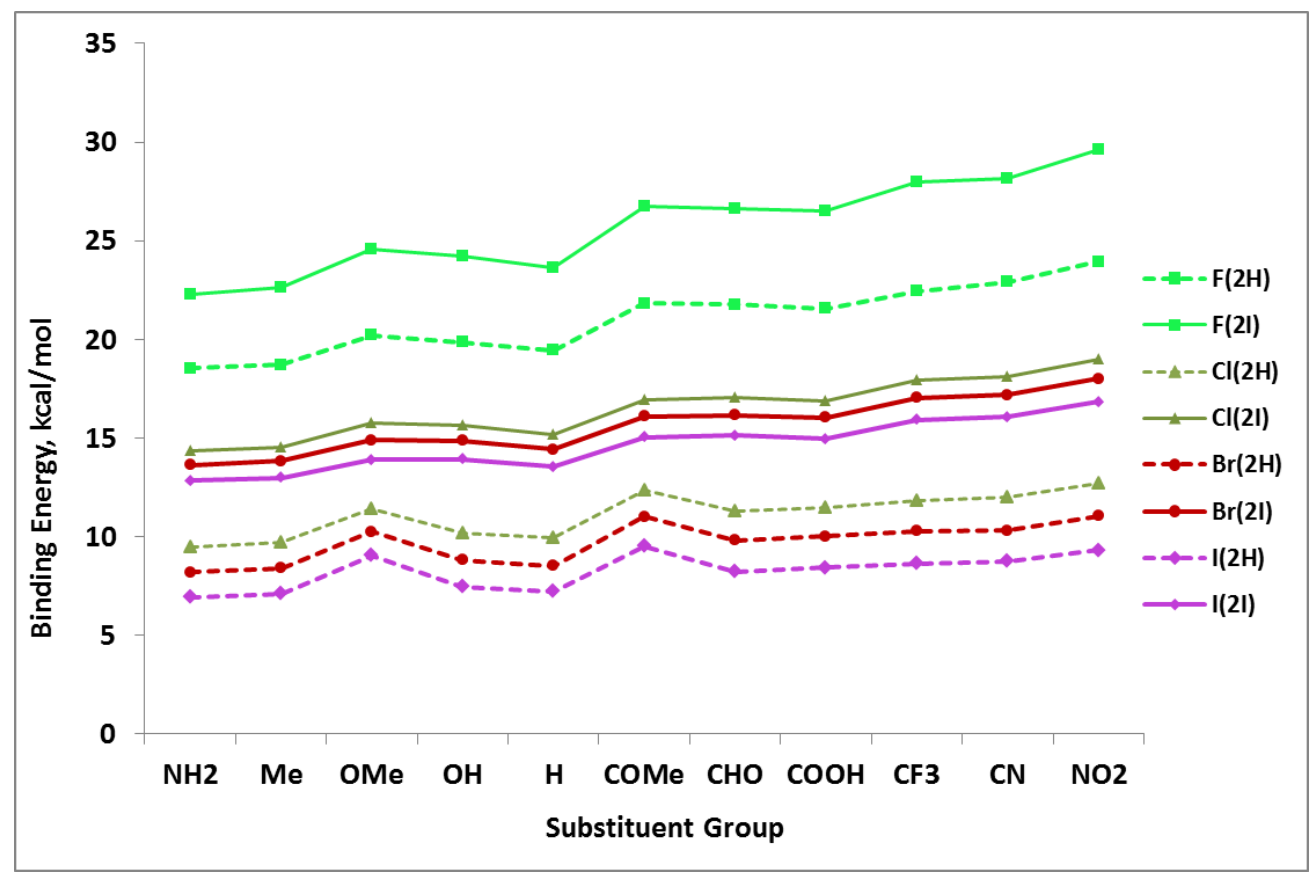

Fig 4. Binding energy of halides $\left(\mathrm{Y}^{-}\right)$to dicationic receptors $\mathrm{BTB}^{+2}$ with different substituent groups $\mathrm{Z}$. $2 \mathrm{H}$ indicates H-bonding complexes $(\mathrm{X}=\mathrm{H})$ and 2I refers to halogen-bonding complexes with $\mathrm{X}=\mathrm{I}$. 


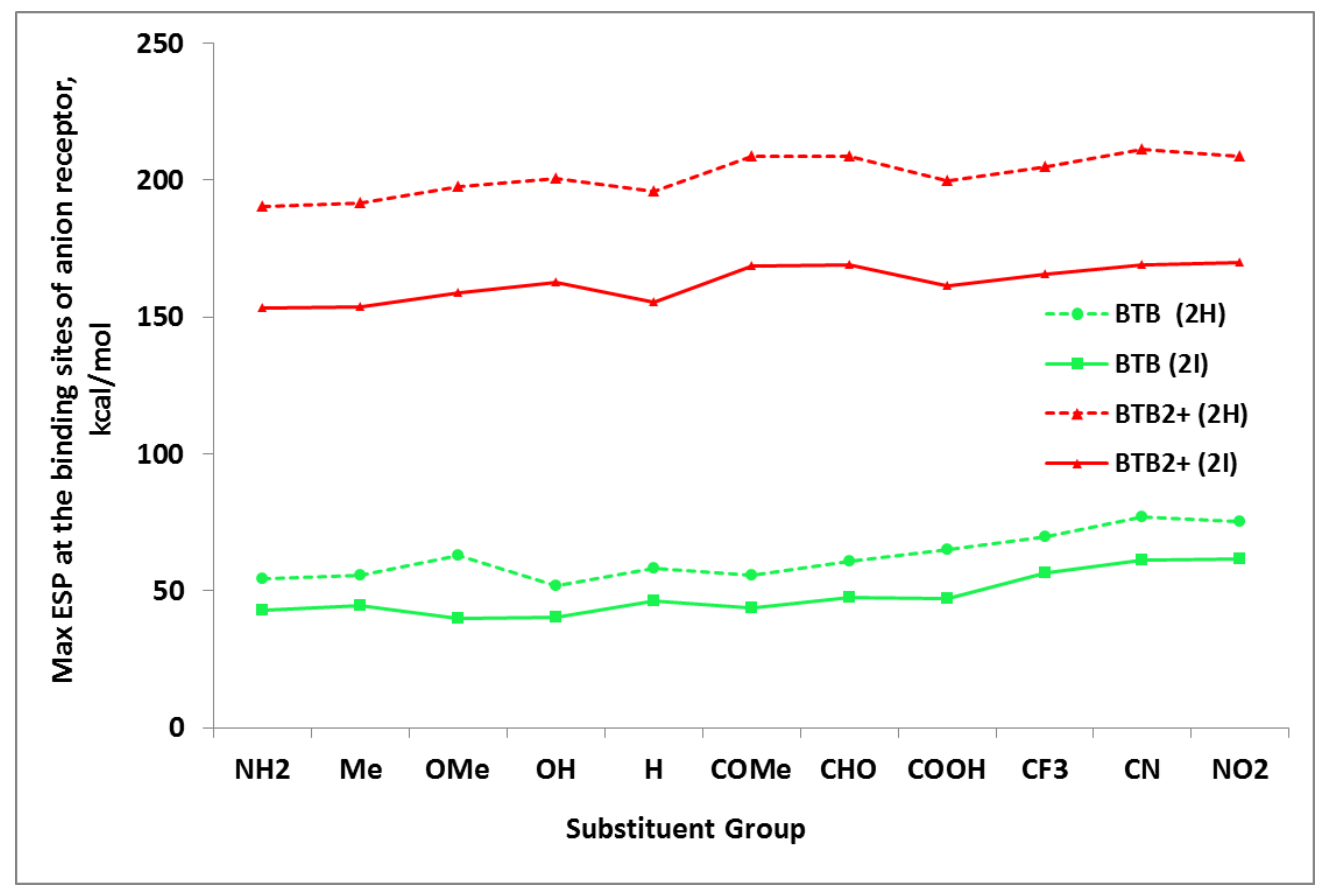

Fig 5. Maximum electrostatic potential at the binding sites of BTB receptors with different substituent groups, $2 \mathrm{H}$ indicates $\mathrm{H}$-bonding receptors and 2I refers to halogen-bonding receptors. 


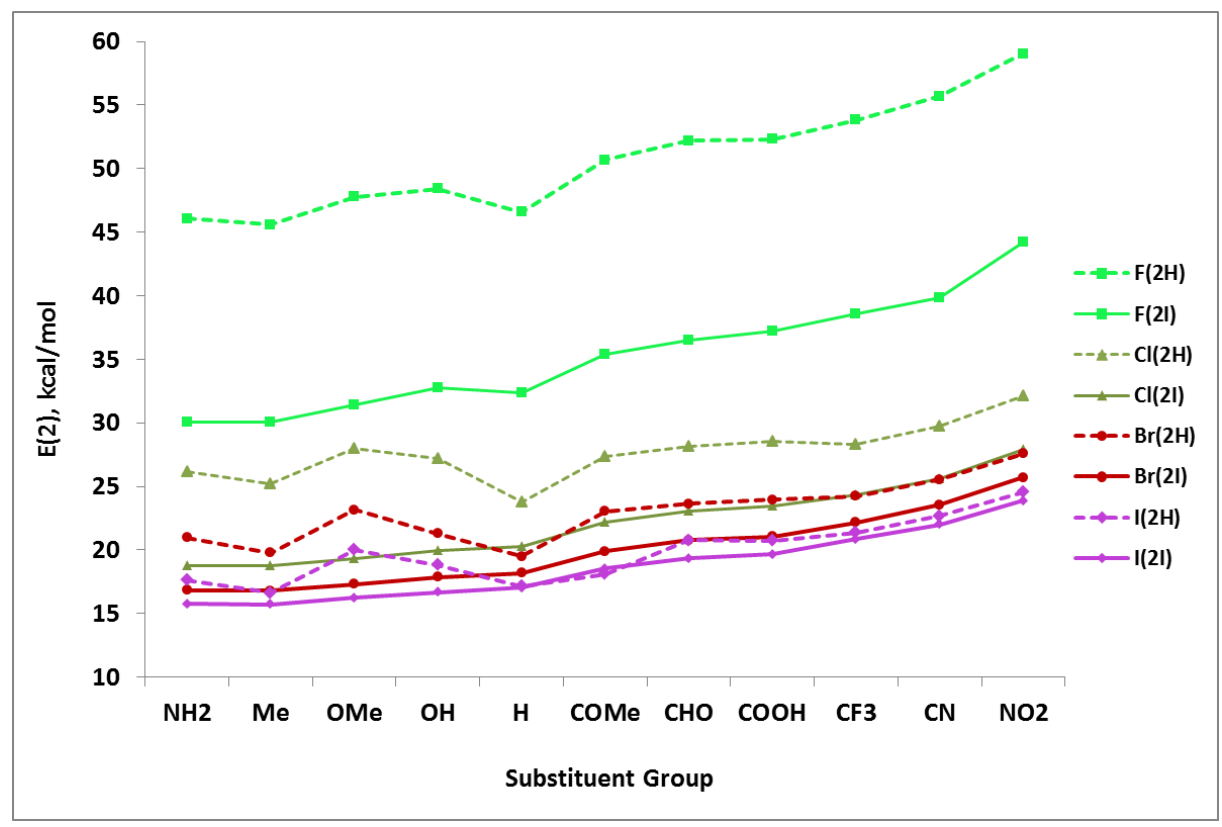

Fig 6. NBO charge transfer energy, $\mathrm{E}(2)$, from halides to $\sigma^{*}(\mathrm{C}-\mathrm{H})$ or $\sigma^{*}(\mathrm{C}-\mathrm{I})$ antibonding orbitals of neutral receptors BTB with different substituent groups $\mathrm{Z}$. 2H indicates $\mathrm{H}$-bonding complexes $(\mathrm{X}=\mathrm{H})$ and $2 \mathrm{I}$ refers to halogen-bonding complexes with $\mathrm{X}=\mathrm{I}$.

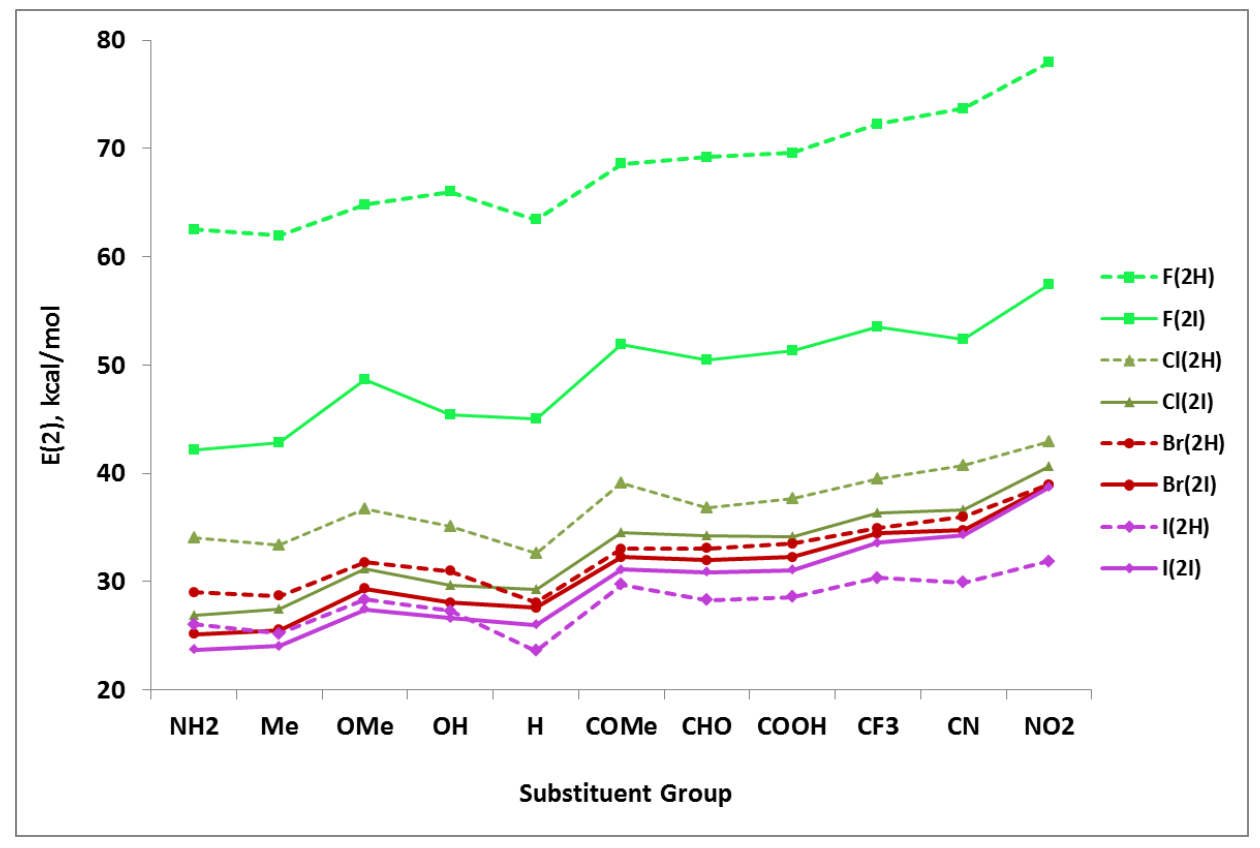

Fig 7. NBO charge transfer energy, $\mathrm{E}(2)$, from halides to $\sigma^{*}(\mathrm{C}-\mathrm{H})$ or $\sigma^{*}(\mathrm{C}-\mathrm{I})$ antibonding orbitals of dication receptors $\mathrm{BTB}^{+2}$ with different substituent groups $\mathrm{Z}$. $2 \mathrm{H}$ indicates $\mathrm{H}$-bonding complexes $(\mathrm{X}=\mathrm{H})$ and $2 \mathrm{I}$ refers to halogen-bonding complexes with $\mathrm{X}=\mathrm{I}$. 


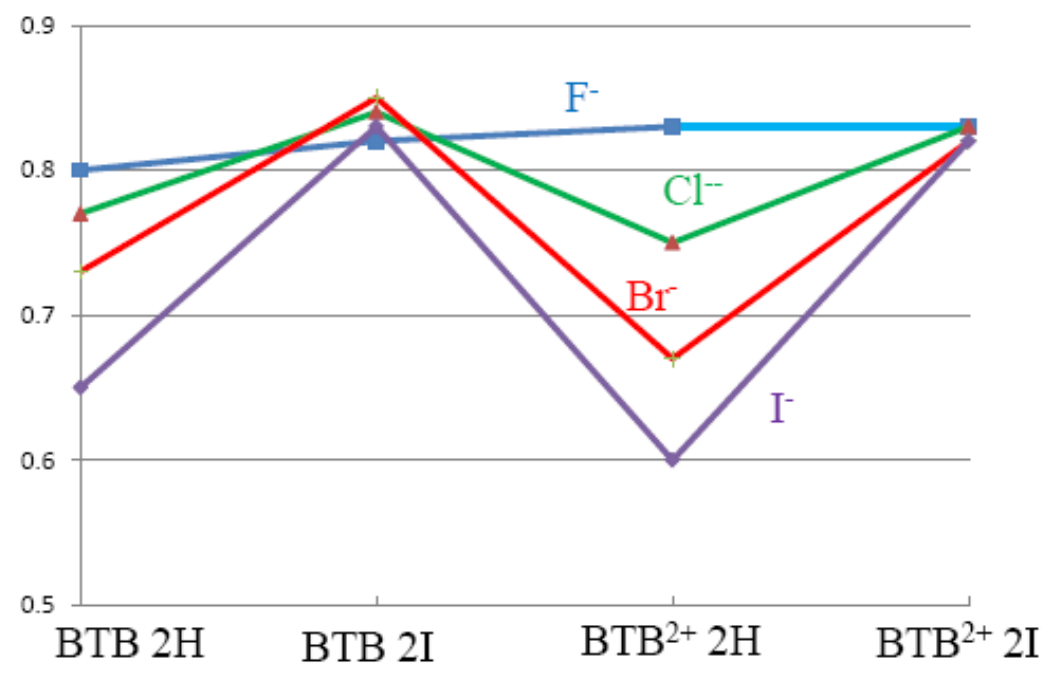

Fig 8. Correlation coefficients $\mathrm{R}^{2}$ between the binding energies of the complexes and maximum MEP of the receptors at the binding sites.

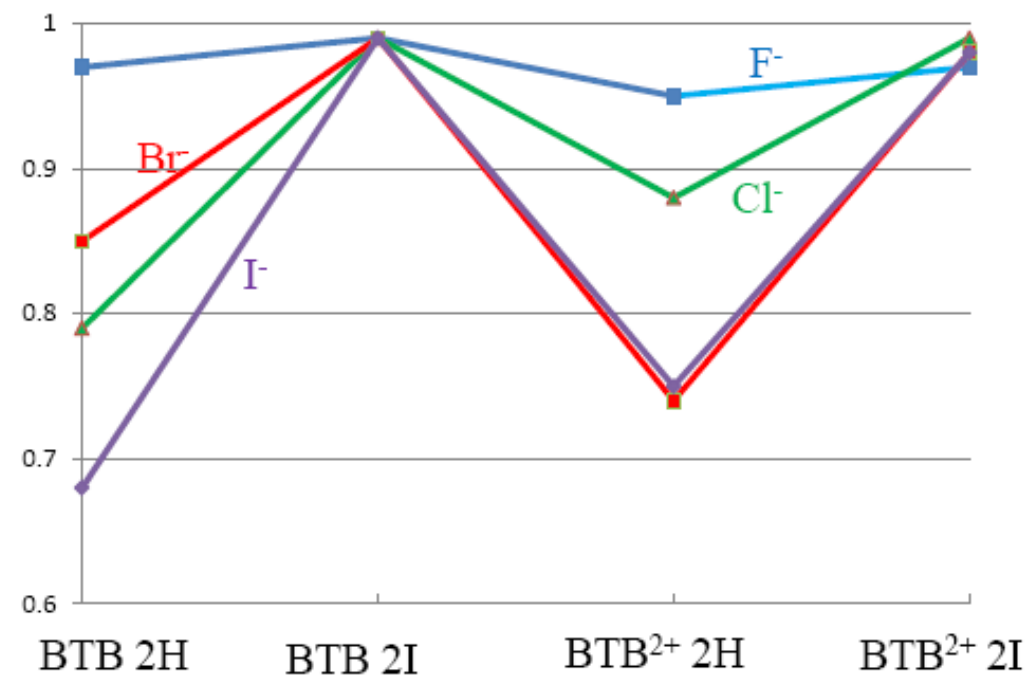

Fig 9. Correlation coefficients $\mathrm{R}^{2}$ between the binding energies of the complexes and NBO charge transfer energies $\mathrm{E}(2)$. 
TOC Graphic

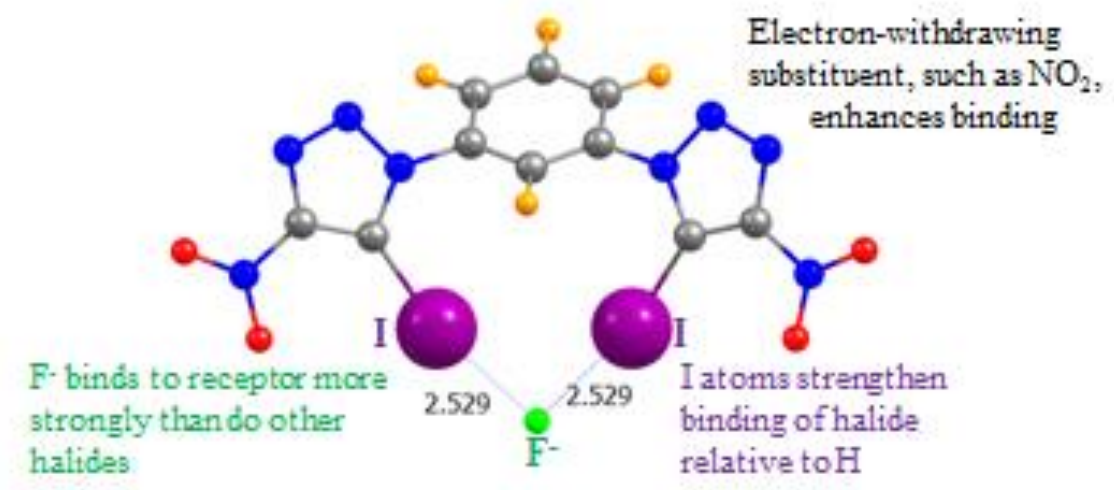

